\title{
Myopathy in association with primary hyperaldosteronism
}

\author{
M. A. SAMBROOK, J. R. HERON, AND G. M. ABER \\ From the Department of Neurology, North Staffordshire Royal Infirmary, Stoke-on-Trent
}

SUMMARY We report a patient presenting with a proximal myopathy in association with primar: hyperaldosteronism (Conn's syndrome). The possible factors concerned in the inter-relationship o⿱ these two conditions are discussed, with particular reference to the influence of potassium depletions

Myopathies have been described in association with several endocrine disorders including thyrotoxicosis (Bathurst, 1895; Ramsay, 1965), myxoedema (Astrom, Kugelberg, and Müller, 1961), hyperparathyroidism (Vicale, 1949), Cushing's syndrome (Müller and Kugelberg, 1959), and hypopituitarism (Shy, 1960; Walton, 1960). Although patients with primary hyperaldosteronism often complain of muscular weakness we are not aware of the electrophysiological, histological, and serum muscle enzyme changes of a degenerative myopathy having previously been described in this condition. We wish therefore to report a patient who presented with a proximal myopathy, in whom further investigation revealed primary hyperaldosteronism. Treatment of the endocrine disorder resulted in a full recovery of his myopathy.

\section{CASE REPORT}

Mr. S. B., a 47 year old plate-maker, was admitted to hospital in September 1970, with a five year history of progressive muscular weakness. Previously as a scout-master he was accustomed to walking several miles at a time but now he was able to maintain a normal pace for only 200 to 300 yards. In particular he noted restriction in climbing stairs and uphill gradients. Increasing weakness of his arms, particularly when elevating them above his shoulders, had curtailed his home-decorating activities. His disability had spontaneously fluctuated in severity and he found that repetitive actions aggravated his weakness. An example of this was the loss of power in his hands which developed after handling large quantities of clay for a day in the course of his job. Also, when stock-taking, which demanded repeated crouching to look at objects on the floor, he developed bilateral foot-drop. Such symptoms would last for several hours. Despite having a good appetite, there had been a gradual wasting of his shoulder muscles and buttocks over the past two years, associated with a loss of two stones $(13 \mathrm{~kg})$ in weight. He has noticed increasing thirst, polyuria, and nocturiais Specific questioning revealed that his bowel habier had remained regular and he had not been taking any drugs or laxatives likely to influence potassiun metabolism.

Apart from the development of bilateral lenticutar cataracts at approximately 20 years of age his pass medical history had been free of any significant 911 으․ ness. A right iridectomy had been performed in 1959 There was no family history of any significant neugological disease.

PHYSICAL EXAMINATION He was of asthenic bod build. His pulse rate was 84 per minute and regularo The blood pressure in both arms was $150 / 100 \mathrm{~mm} \mathrm{Hg}$ The apex beat of the heart was of normal charactep and situated in the fifth left intercostal space in the् mid-clavicular line. Auscultation of the heart was normal. No abnormality was found in the chest of abdomen.

CENTRAL NERVOUS SYSTEM His intellect and memory were unimpaired, and his speech was normal. He had a cataract of the left lens. Full examination of the cranial nerves revealed no abnormality and theres was no evidence of facial weakness. There was proximal weakness of his arms and legs with paro ticular involvement of the deltoid, triceps, biceps $\rightarrow$ spinati, pelvic girdle, and thigh muscles. Wasting. was noted over the shoulder girdle muscles and the buttocks. Muscular tone and tendon reflexes were normal and the plantar responses were bilaterallyo flexor. Sensory testing revealed no abnormality.

At the time of admission the following investiga tions were made.

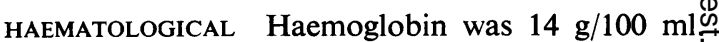
and the white blood cell count was 7,900 per cu.mm, 
with a normal differential count; erythrocyte sedimentation rate was $5 \mathrm{~mm}$ in the first hour.

BIOCHEMICAL The following estimations were made: serum urea $45 \mathrm{mg} / 100 \mathrm{ml}$, potassium $2.0 \mathrm{~m}$-equiv/l., sodium 146 m-equiv/l., chloride 98 m-equiv/l.; calcium $9.3 \mathrm{mg} / 100 \mathrm{ml}$., phosphate $3.2 \mathrm{mg} / 100 \mathrm{ml}$., blood $\mathrm{pH} 7.52 ; \mathrm{pCO}_{2} 48 \mathrm{~mm} \mathrm{Hg}$; standard bicarbonate $34 \mathrm{~m}$-equiv/l.; serum albumin $4.6 \mathrm{~g} / 100 \mathrm{ml}$.; globulin $2.0 \mathrm{~g} / 100 \mathrm{ml}$; 位irubin $0.3 \mathrm{mg} / 100 \mathrm{ml}$; serum creatinine $1.4 \mathrm{mg} / 100 \mathrm{ml}$; with a creatinine clearance of $57 \mathrm{ml} . / \mathrm{min}$. Glucose tolerance test was normal. Protein bound iodine level was $7 \cdot 5 \mu \mathrm{g} / 100$ ml.; serum T3- ${ }^{131}$ I resin uptake $26 \cdot 7 \%$. Plasma cortisol at 0900 hours was $9 \mu \mathrm{g} / 100 \mathrm{ml}$; ; 2400 hours $3 \mu \mathrm{g} / 100 \mathrm{ml}$.; plasma aldosterone was $69 \mathrm{~m} \mu \mathrm{g} / 100 \mathrm{ml}$. (normal up to $18 \mathrm{~m} \mu \mathrm{g} / 100 \mathrm{ml}$.) and plasma renin 4.2 u./l. (normal 4 to 20 u./1.). The plasma renin and aldosterone estimations were both made after the patient had been in hospital for three weeks on a regulated dietary intake of sodium, 150 m-equiv per day, and potassium, 60 m-equiv per day. The blood was taken while the patient was in the supine position and after 12 hours fasting.

Enzyme levels relevant to neuromuscular disease were: serum creatinine phosphokinase 882 i.u./l.; serum aldolase $6.5 \mathrm{u} . / \mathrm{ml}$.; serum glutamic-oxaloacetic transaminase $45 \mathrm{u}$./ml.; serum glutamic-pyruvate transaminase $20 \mathrm{u} . / \mathrm{ml}$.

ELECTROMYOGRAPHY Sensory nerve conduction times were determined in both median, ulnar, and lateral popliteal nerves. The resultant sensory nerve action potentials were all of normal amplitude and delay. Motor conduction velocities in both median and ulnar nerves ranged between 45 and $50 \mathrm{~m} / \mathrm{sec}$. Motor conduction velocity in the right and left lateral popliteal nerves was 43 and $45 \mathrm{~m} / \mathrm{sec}$ respectively. Electromyographic (EMG) sampling was performed in the deltoid and vastus medialis muscles bilaterally. At all sampling sites there was no excess of post-insertional activity. No spontaneous fibrillation or fasciculation potentials were noted at rest. On volition a full interference pattern was found at all sites but there was a reduction in the amplitude and duration of many of the individual motor unit potentials. Tetanic stimulation at 20 impulses per second revealed a gradual but fluctuating decay in the resultant muscle action potential. This was not reversed by intravenous edrophonium. With suitable exercise we were able to induce bilateral foot-drop. Further EMG sampling particularly from the tibialis anterior and extensor hallucis longus muscles showed abnormal individual motor unit action potentials and a reduction in the interference pattern. There was no reduction in the motor conduction velocity of either lateral popliteal nerve at this time.

MUSCLE HISTOLOGY A muscle biopsy was taken from the left deltoid muscle. Staining with trichrome and
DPNH tetrazolium reductase showed some muscle fibres in various stages of necrosis with centralization of nuclei in other fibres (Figs 1 and 2). No mononuclear or macrophage infiltration into the involved muscle was seen.

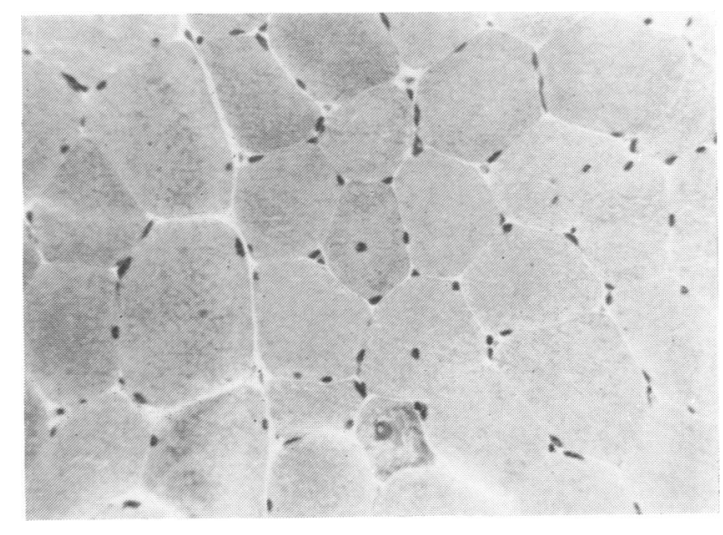

FIG. 1. Trichrome, $\times 125$.

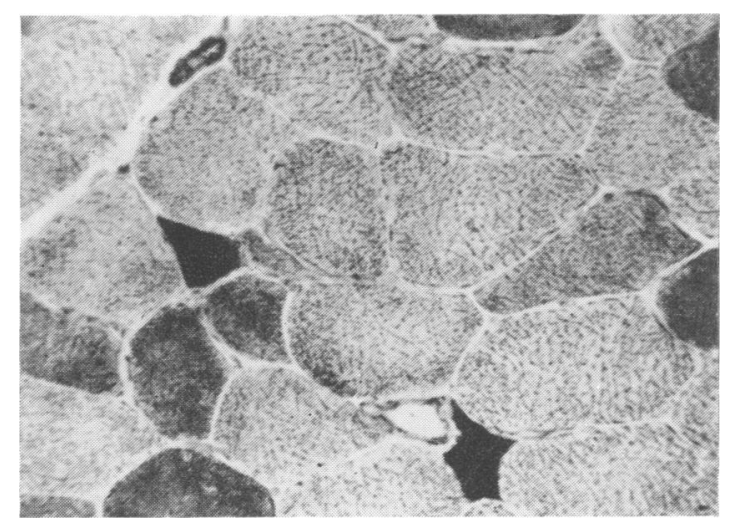

FIG. 2. DPNH tetrazolium reductase, $\times 125$.

FIGS 1 and 2. Transverse sections of left deltoid muscle before treatment with spironolactone showing degenerating fibres and centralization of nuclei.

ELECTROCARDIOGRAPHY There was evidence of left ventricular hypertrophy and strain with ' $U$ ' waves in leads II, III, $\mathrm{V}_{3}, \mathrm{~V}_{4}, \mathrm{~V}_{5}$, and $\mathrm{V}_{6}$.

RADIOLOGY Radiographs of the chest showed a cardiothoracic ratio of $50 \%$. An intravenous pyelogram revealed normal concentration and excretion by both kidneys.

EFFECT OF TREATMENT WITH SPIRONOLACTONE During the period of investigation the patient was main- 


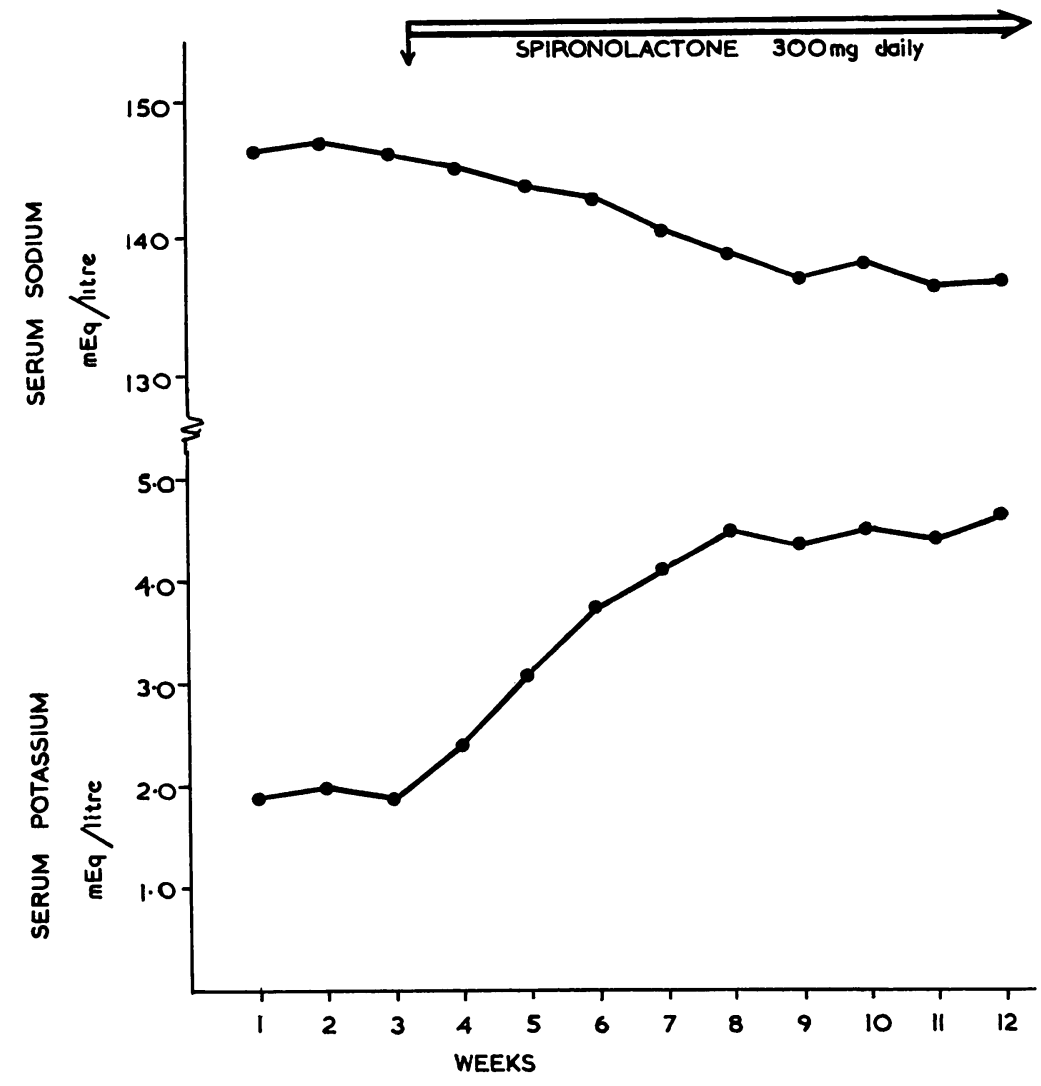

FIGS 3 and 4. Serum se dium and potassium, blosd $p H$, and bicarbonate befo $\overline{\bar{C}^{2}}$ and during treatment with spironolactone.

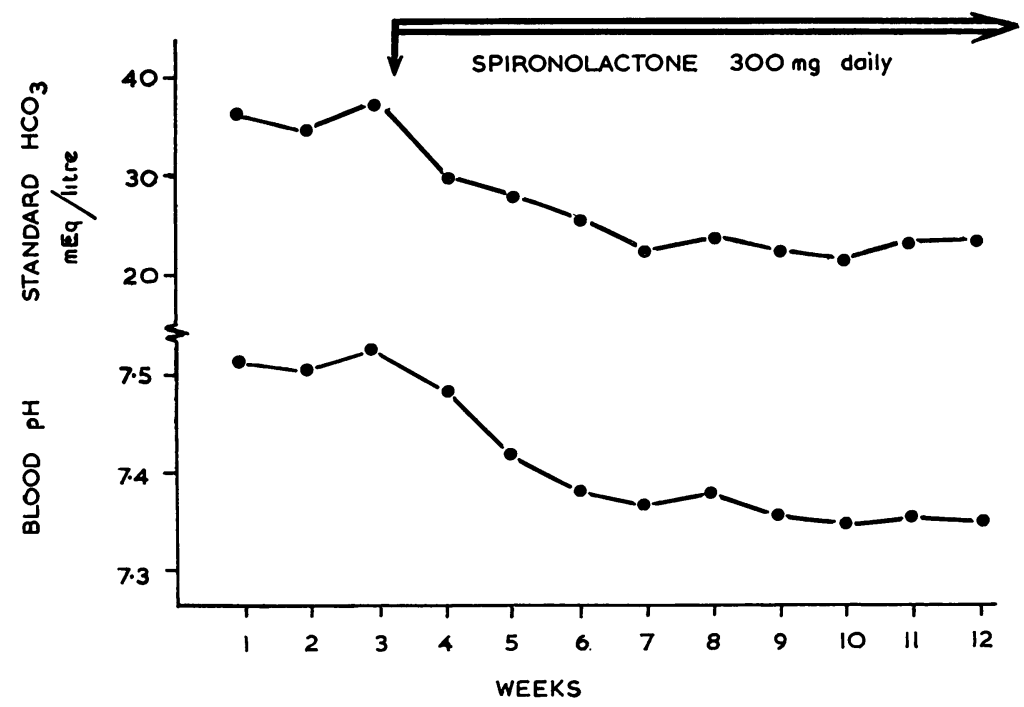


tained on a daily intake of 150 m-equiv of sodium and $60 \mathrm{~m}$-equiv of potassium. He was observed for three weeks before treatment with spironolactone was started and his serum electrolyte and acid-base abnormalities remained unchanged (Figs 3 and 4). Cumulative balance studies of sodium and potassium were started 10 days before commencement with spironolactone. During this 'control' period he was noted to be in zero balance for potassium and in positive balance for sodium despite a serum potassium level of only $2 \mathrm{~m}$-equiv/l. and a serum sodium of $146 \mathrm{~m}$-equiv/l. (Figs 5 and 6).

After this observation period the patient received $300 \mathrm{mg}$ spironolactone daily for three months. During the first 10 days of treatment he retained 350 m-equiv of potassium and developed a negative balance of 330 m-equiv sodium (Figs 5 and 6), while

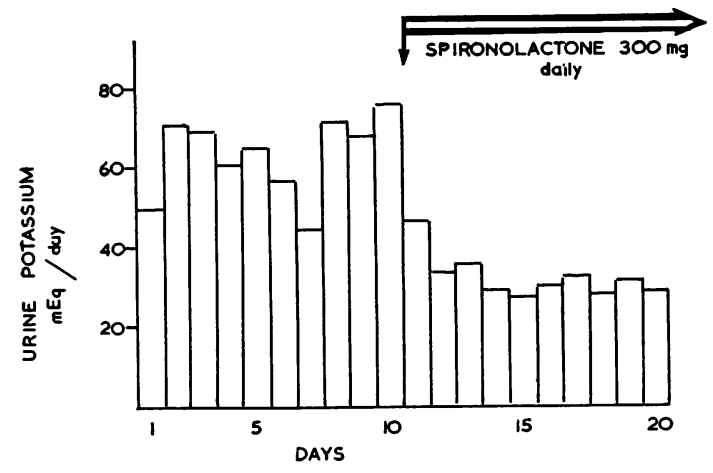

FIG. 5

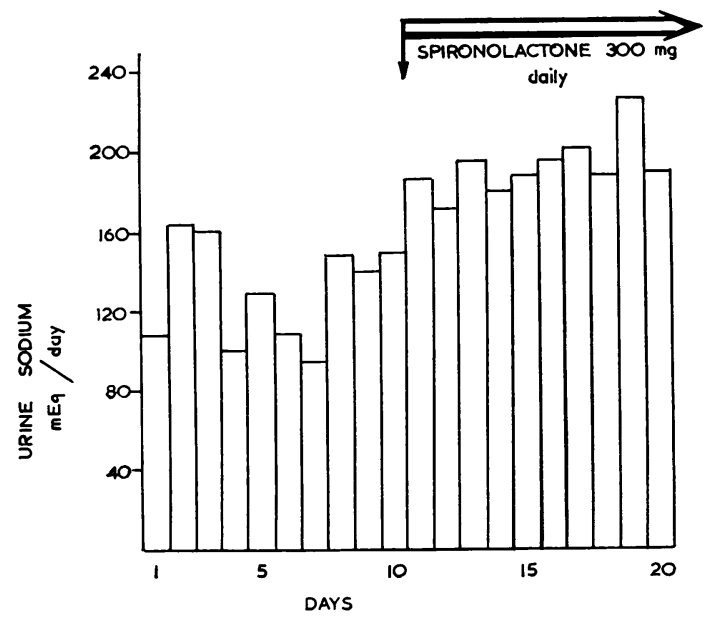

FIG. 6

FIGS 5 and 6. Daily urinary excretion of potassium and sodium for 10 days before and during first 10 days of treatment with spironolactone. his serum potassium increased to $3 \mathrm{~m}$-equiv/l. and his serum sodium decreased to $144 \mathrm{~m}$-equiv/l. (Figs 3 and 4). At the end of this period he was still accumulating $30 \mathrm{~m}$-equiv potassium and losing $30 \mathrm{~m}$ equiv sodium daily. Only slight improvement in his muscle function was observed during this time.

After four weeks of treatment his serum potassium, sodium, and standard bicarbonate stabilized at $4 \cdot 5$, 138, and 22 m-equiv/1. respectively (Figs 3 and 4). There was a marked improvement in his muscular power and repeat estimation of his muscle enzymes revealed that the serum creatinine phosphokinase had fallen to $30 \mathrm{i} . u . / 1$. and the serum aldolase was now $2.9 \mathrm{u}$./ml. Further electromyographic studies were made and these showed a disappearance of the abnormal motor unit potentials which had originally been observed.

Although balance studies were discontinued, he continued to receive spironolactone for another eight weeks as an outpatient. There was a further subjective improvement in his muscular power and at the end of this period he felt that he had made a complete recovery. He was employed as a piece worker and now that he had returned to work he was able to earn $£ 5$ per week extra compared with his performance before hospital admission. On clinical examination muscular power was now normal and the wasting of the shoulder muscules and buttocks was less marked. A second muscle biopsy was taken from the opposite deltoid muscle and this revealed no abnormality.

At this stage a laparotomy was performed at which a tumour of the left adrenal gland was found $(2 \times 1$ $\mathrm{cm}$ ), and a left adrenalectomy performed. Postoperatively the spironolactone was discontinued. During the six months postoperative follow-up period he has shown no evidence of deterioration of muscular power or return of his original electrolyte derangement.

Histology of the left adrenal tumour showed a well-circumscribed adenoma consisting mainly of zona fasciculata type cells with some 'hybrid' cells as typically described in Conn's tumours. Histological examination of a renal biopsy taken at the time of laparotomy showed arteriolar hypertrophy and renal tubular dilatation and atrophy with a moderate amount of interstitial fibrosis and focal lymphocytic reaction. These findings were felt to be consistent with long-standing hypertension.

\section{DISCUSSION}

In 1964 Conn, Knopf, and Nesbit discussed the clinical presentation and findings in their series of 145 cases of primary hyperaldosteronism. One of the most common initial symptoms in their patients was muscular weakness $(73 \%)$ typically fluctuant in severity. Analysing their data, we 
were unable to find criteria to suggest that any of their patients had a degenerative myopathy, and they attributed the muscular weakness to hypokalaemia.

We have studied a patient whose main complaint was of longstanding muscular weakness. Neurological examination and investigations revealed that he had a proximal myopathy which was confirmed histologically, and biochemical investigation showed that he had primary hyperaldosteronism. During treatment with spironolactone for 12 weeks his biochemical disturbance was corrected and there was a complete recovery of his muscular power with disappearance of the biochemical, electromyographic, and histological evidence upon which we had originally based our diagnosis of myopathy, suggesting that this was directly related to his endocrine disorder.

Analysis of the biochemical changes which occurred during the period of spironolactone therapy showed a striking retention of potassium. The balance studies showed an elevation of his serum potassium from 2 to 3 m-equiv/l. during the first 10 days of treatment in association with retention of 350 m-equiv potassium. It is probable that this figure would be much greater by the time his serum value had reached the final stable level of 4.5 m-equiv/l. Of this total potassium only $10 \%$ could be accounted for in the extracellular fluid, suggesting that the rest had entered the intracellular compartment. These figures are consistent with those of Scribner and Burnell (1956) who showed that a serum potassium of $2 \mathrm{~m}$-equiv/l. usually indicated a total body loss of approximately 500 to 600 m-equiv. In addition to changes in his body potassium, treatment produced a simultaneous correction of his sodium and acid-base disturbances.

The role of potassium in the regulation of muscular function is well established. The intrato extracellular concentration has been shown to be vital for the control of the resting membrane potential of muscle fibres. This potential is elevated in hypokalaemia, resulting in a decreased muscle excitability and contractility which is one of the major factors responsible for the weakness observed in potassium depletion. Evidence has also accumulated that potassium is necessary for intracellular metabolism. It is required for the phosphorylation of high energy compounds such as creatinine phosphate and adenosine triphosphate (Boyer, Lardy, and Phillips, 1943) and it has been shown experimentally that when rats are depleted of potassium, growth and protein synthesis cannot proceed normally (Cannon, Frazier, and Hughes, 1952 Structural disintegration of muscle may develoq and Smith, Black-Schaffer, and Lasater (195\%) were able to demonstrate the development of severe muscular weakness followed by respirß tory paralysis in dogs depleted of potassiun Examination of the skeletal muscle fibres showed Zenker's hyaline degeneration with infiltratio by mononuclear cells. In man necrosis of cardiac muscle fibre has been reported in conditions ff acute and chronic hypokalaemia (Rodrique

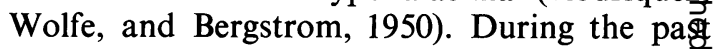
five years several case reports have appeared of acute myopathies associated with hypokalaemia after abuse of laxatives, carbenoxolone and diuretics (Gross, Dexter, and Roth, 1966. Mohamed, Chapman, and Crooks, 1966; Fo? shaw, 1969; Van Horn, Drori, and Schwart 1970). In all these cases there was histologicab evidence of muscle fibre necrosis and elevated serum muscle enzymes. Potassium repletion rê sulted in recovery of muscular power and the disappearance of the histological abnormalitie These observations, taken in conjunction the findings in our patient, are strongly sugges that potassium depletion may well have the major factor responsible for the developresi of his myopathy but it is important to realize that during the corrective period there was a marked loss of sodium and striking changes in hydroge ion concentration, and at present neither $\bar{Q}$ these can be disregarded when considering the aetiology of the myopathy.

More extensive investigation of patients wi Conn's syndrome may reveal further cases $\Theta$ associated myopathy and it is interesting speculate on the possible influence of electroly disturbances in the causation of myopathies see in association with Cushing's syndrome and with corticosteroid therapy.

We wish to thank Dr. J. Morgan Hughes for pre paring the muscle histology; Mr. J. G. Gray for details of the surgical procedure, and Dr. J. J. $\$$ Robertson of the M. R. C. Blood Pressure Un Western Infirmary, Glasgow, for the plasma renjy and aldosterone estimations.

\section{REFERENCES}

Astrom, K.-E., Kugelberg, E., and Müller, R. (1961). Hypothyroid myopathy. Archives of Neurology, 5, 472-482.

Bathurst, L. W. (1895). A case of Graves' disease associat with idiopathic muscular atrophy. Remarks. Lancet, II, 529-530. 
Boyer, P. D., Lardy, H. A., and Phillips, P. H. (1943). Further studies on the rôle of potassium and other ions in the phosphorylation of the adenylic system. Journal of Biological Chemistry, 149, 529-541,

Cannon, P. R., Frazier, L. E., and Hughes, R. H. (1952). Influence of potassium on tissue protein synthesis. Metabolism, 1, 49-57.

Conn, J. W., Knopf, R. F., and Nesbit, R. M. (1964). Clinical characteristics of primary aldosteronism from an analysis of 145 cases. American Journal of Surgery, 107, 159-172.

Forshaw, J. (1969). Muscle paresis and hypokalaemia after treatment with duogastrone. British Medical Journal, 2, 674.

Gross, E. G., Dexter, J. D., and Roth, R. G. (1966). Hypokalemic myopathy with myoglobinuria associated with licorice ingestion. New England Journal of Medicine, 274, 602-606.

Mohamed, S. D., Chapman, R. S., and Crooks, J. (1966). Hypokalaemia, flaccid quadraparesis, and myoglobinuria with carbenoxolone (Biogastrone). British Medical Journal, 1, $1581-1582$.

Müller, R., and Kugelberg, E. (1959). Myopathy in Cushing's syndrome. Journal of Neurology, Neurosurgery, and Psychiatry, 22, 314-319.

Ramsay, I. D. (1965). Electromyography in thyrotoxicosis. Quarterly Journal of Medicine, 34, 255-267.
Rodriguez, C. E., Wolfe, A. L., and Bergstrom, V. W. (1950). Hypokalemic myocarditis: report of two cases. American Journal of Clinical Pathology, 20, 1050-1055.

Scribner, B. H., and Burnell, J. M. (1956). Interpretation of the serum potassium concentration. Metabolism, 5, 468479.

Shy, G. M. (1960). Some metabolic and endocrinological aspects of disorders of striated muscle. Research Publications, Association for Research in Nervous and Mental Disease, 38, 274-317.

Smith, S. G., Black-Schaffer, B., and Lasater, T. E. (1950). Potassium deficiency syndrome in the rat and the dog. Archives of Pathology, 49, 185-199.

Van Horn, G., Drori, J. B., and Schwartz, F. D. (1970). Hypokalemic myopathy and elevation of serum enzymes. Archives of Neurology, 22, 335-341.

Vicale, C. T. (1949). The diagnostic features of a muscular syndrome resulting from hyperparathyroidism, osteomalacia due to renal tubular acidosis, and perhaps to related disorders of calcium metabolism. Transactions of the American Neurological Association, 74, 143-147.

Walton, J. N. (1960). Muscular dystrophy and its relation to the other myopathies. Research Publications, Association for Research in Nervous and Mental Disease, 38, 378-421, 